\title{
Degree of Injury on Visum et Repertum
}

\author{
Mohd Hadyan Wardhana ${ }^{1}$ and Syarifah Hidayah Fatriah ${ }^{2 *}$ \\ ${ }^{1}$ Faculty of Information and Communication Technology, University Technical of Malaysia Malacca, Indonesia \\ ${ }^{2}$ Departement of Forensic Medicine and Medicolegal Faculty of Medicine, University of Riau, Indonesia
}

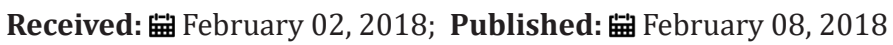

*Corresponding author: Syarifah Hidayah Fatriah Departement of Forensic Medicine and Medicolegal Faculty of Medicine, University of Riau, Indonesia

\begin{abstract}
Visum et Repertum is a written statement made by a doctor at the request of authorized investigators about the results of medical examinations of humans, whether alive or dead or part or parts of the human body are suspected, based on their knowledge and under oath, to the benefit of Justice.
\end{abstract}

Keywords: Visum et Repertum; Degree of injury; Forensic clinic; Health care

Abbreviations: ISS: Injury Severity Score; AIS: Abbreviated Injury Scale; NISS: New Injury Severity Score; TRISS: Trauma Related Injury Severity Score; ICISS: Injury Severity Score; SRR: Survival Risk Ratio; RTS: Revised Trauma Score; MTOS: Major Trauma Outcome Study

\section{Introduction}

One that must exist at the conclusion of Visum et Repertum survivors of abuse cases is the degree of injury. There are three types of degrees injury, which are minor, moderate, and severe. The degree of the injury is related to the type of criminal offenses committed by the offender and the severity of the maximum criminal penalty that can be imposed on the offender [1].

\section{Discussion}

There is no clear explanation of the degree of injury as described above leads to conclusions made by individual examining physicians may differ. Although in practice Indonesia has used a benchmark in determining the degree of injury, but the determination of the degree of injury in certain cases can occur dissent among doctors. Errors in the determination of the degree of injury can lead to injustice for victims and perpetrators of criminal acts. The inaccurate determination of the degree of injury will have an impact on the criminal provisions that will be applied to the case, which will subsequently affect the magnitude of the criminal threat to be imposed on the offender. Under the Penal Code it is stated that the perpetrators of light maltreatment are sentenced to imprisonment for 3 months, the perpetrator shall be sentenced to imprisonment for 2 years and 8 months, and the sentence can be increased up to 5 years if the victim is seriously injured [2-5].
In 1974, Baker have found the degree of injury to classify trauma victims based on the severity of the injury known as the Injury Severity Score (ISS), which is based on the value of the Abbreviated Injury Scale (AIS), which had the wound by scoring the severity of anatomy [6] parameter ISS scores highly correlate with the probability of survival of the traumatized patient. The ISS uses six different regions of the head and neck, face, chest, abdomen or pelvic contents, extremities, and external structures. ISS scoring with description are minor, moderate; severe, not life-threatening; severe, life-threatening; critical, survival uncertain; un survivable [7].

The weakness of ISS if there is severe multiple injury to one body region and the ISS gives equal weight to each body region, for example: AIS 3 score in the chest region will give a different prognosis when compared with AIS 3 score in the head region. Other examples: AIS 5 score in the chest region will provide a different prognosis when compared to the AIS score of 5 in the head region [7] In 1997, to improve the limitations of ISS was found New Injury Severity Score (NISS) which sums the quadrants of the three injuries that have the most AIS scores higher regardless of whether it comes from a different region [8]. 
The difference between the ISS is that NISS sees only the degree of severity of the injury to account for the different multiple surfaces in one region of the body. In addition, there are scores of injury degrees based on a combination of physiological and anatomical parameters which have two well-known first Trauma Related Injury Severity Score (TRISS) and International Classification of Disease, 9th revision, Injury Severity Score (ICISS) [5].

An injury severity assessment method is important to predict the outcome of an injury. Differences in criteria used for assessment of injury are necessary because they are associated with possible mortality, cost, reliability, quality of life, and disability. Methods used include ICISS (ICD-based Injury Severity Score) which involves the value of Survival Risk Ratio (SRR) which calculates the life expectancy ratio for individual (ratio of the number of patients with surviving injury code compared to the total number of patients who has been diagnosed with the code). The ICISS score comes from ICD-10-AM which contains code due to injuries suffered [9] ICSS is also combined with the age and score of Revised Trauma Score (RTS) in an analytical approach is similar to Trauma Related Injury Severity Score (TRISS) analysis. This method has a superior and better prediction compared to TRISS.10 The ICISS scoring method was introduced by Rutledge et al and claimed to provide a better prediction of trauma outcome than the TRISS scoring method with the application of the neural network information system. Limitations of ICISS methods are:

a) Recording of deaths occurring only in hospitals.

b) Limitations in identifying patients.

c) Affected by SRR value.

d) Excluded from the diagnosis of injury (co morbid factor).

e) Some studies have found that ICISS values have the same values as SRR when compared to the SRR value ratio to obtain ICISS values.

Assessment of SRR or ICISS utilizes physiological factors and aims to detect predictions of trauma outcomes, so it is more appropriate to use for moderate to severe injuries. The method and the like are not beneficial for minor injuries. TRISS method known around 1981, this method using database from Major Trauma Outcome Study (MTOS). TRISS has a deficiency in describing injuries that occur until the problem does not consider aspects of the medical condition / patient disease that already existed $[10,11]$. Research in Indonesia on the method of determining the degree of minor injuries and injuries was done with the scoring method TRISS and total wound.

\section{Conclusion}

Determination of injury degree at the conclusion of current Visum et Repertum is still determined based on the scholarship and experience of the examining physician. Advanced research is needed to assist physicians in determining the degree of injury that can distinguish the degree of minor, moderate and severe injuries seen from anatomical and physiological aspects.

\section{References}

1. (1997) Forensic Medicine Section Faculty of Medicine University of Indonesia. Forensic Medicine Science.

2. Herkutanto (2005) Improvement of quality of visum et repertum (VeR) injury in hospital through emergency room doctor training (ER), JPMK 8 (3): 163-169.

3. Afandi D (2010) Visum et repertum: the medicolegal aspect and the determination of wound degree. Maj KedoktIndon 60 (4): 188-95.

4. Herkutanto (2004) The quality of visum et repertum injured in Jakarta and the factors that influence it. Indonesian Medical Magazine 54 (9): $355-60$.

5. Sugiharto AF (2009) Method of diagnosis of mild and moderate wound degree using TRISS as the basis of the objectivity of the conclusion of visum et repertum [thesis]. Jakarta: University of Indonesia.

6. Injury Severity Score. The document contains a thorough review of different injury severity scores employed in trauma care, their classification based on anatomic and physiologic scale and a collection of abstracts from research papers highlighting.

7. Institute of Trauma and Injury Management. Injury Severity Score.

8. Copes WS, Sacco WJ, Champion HR, Bain LW (1989) "Progress in Characterizing Anatomic Injury", In Proceedings of the $33^{\text {rd }}$ Annual Meeting of the Association for the Advancement of Automotive Medicine, Baltimore, USA 205-218.

9. Henly G Harrison JE (2009) Injury Severity Scaling A comparison of methods for measurement of injury severity. Canberra, Australia.

10. Pohlman THP (2014) Trauma Scoring System.

11. Champion HR (2002) Trauma Scoring. Scandinavian Journal of Surgery 91(1): 12-22.

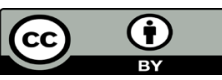

This work is licensed under Creative Commons Attribution 4.0 License

To Submit Your Article Click Here: Submit Article DOI: $10.32474 /$ PRJFGS.2018.01.000103

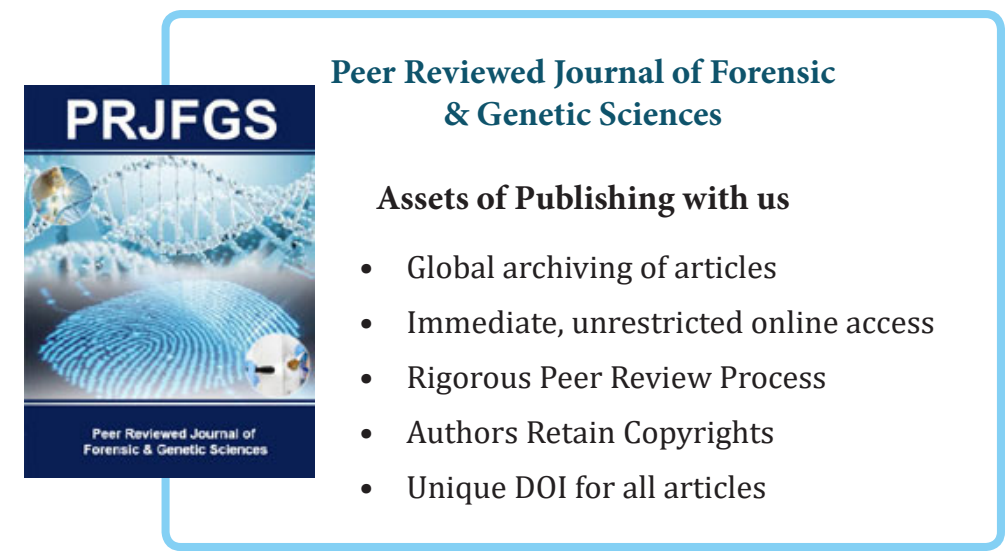

